\title{
AUTOLOGOUS PORCINE HEART CELL TRANSPLANTATION IMPROVED HEART FUNCTION AFTER A MYOCARDIAL INFARCTION
}

Ren-Ke Li, MD, PhD

Richard D. Weisel, MD

Donald A. G. Mickle, MD

Zhi-Qiang Jia, MD

Eung-Joong Kim, MD

Tetsuro Sakai, MD

Shinji Tomita, MD

Leonard Schwartz, MD

Mark Iwanochko, MD

Mansoor Husain, MD

Robert J. Cusimano, MD, MSc

Robert J. Burns, MD

Terrence M. Yau, MD, MSc
Objective: Fetal cardiomyocyte transplantation improved heart function after cardiac injury. However, cellular allografts were rejected despite cyclosporine (INN: ciclosporin) therapy. We therefore evaluated autologous heart cell transplantation in an adult swine model of a myocardial infarction. Methods: In 16 adult swine a myocardial infarction was created by occlusion of the distal left anterior descending coronary artery by an intraluminal coil. Four weeks after infarction, technetium 99m-sestamibi single photon emission tomography showed minimal perfusion and viability in the infarcted region. Porcine heart cells were isolated and cultured from the interventricular septum at the time of infarction and grown in vitro for 4 weeks. Through a left thoracotomy, either cells $(\mathbf{N}=8)$ or culture medium $(\mathbf{N}=8)$ was injected into the infarct zone. Results: Four weeks after cell transplantation, technetium 99m-sestamibi single photon emission tomography demonstrated greater wall motion scores in the pigs receiving transplantation than in control animals $(P=$ .01). Pigs receiving transplantation were more likely to have an improvement in perfusion scores $(P=.03)$. Preload recruitable stroke work $(P=$ $.009)$ and end-systolic elastance $(P=.02)$ were greater in the pigs receiving transplantation than in control animals. Scar areas were not different, but scar thickness was greater $(P=.02)$ in pigs receiving transplantation. Cells labeled with bromodeoxyuridine in vitro could be identified in the infarct zone 4 weeks after transplantation. Swine receiving transplantation gained more weight than control animals $(P=.02)$. Conclusion: Autologous porcine heart cell transplantation improved regional perfusion and global ventricular function after a myocardial infarction. (J Thorac Cardiovasc Surg 2000;119:62-8)
$\mathrm{R}^{\mathrm{n}}$ ecent studies of cell transplantation into the myocardium $^{1-3}$ have suggested that transplanted cells may replace infarcted myocardium or serve as a platform for therapeutic gene transfer to the myocardium. ${ }^{3,4}$ Either cell or gene therapy may improve postinfarct cardiac performance. Previous studies have report-

From the Divisions of Cardiovascular Surgery and Cardiology, Department of Clinical Biochemistry, Toronto General Hospital, University Health Network, Toronto, Ontario, Canada.

Read at the Seventy-ninth Annual Meeting of The American Association for Thoracic Surgery, New Orleans, La, April 18-21, 1999.

Received for publication April 22, 1999; revisions requested May 14, 1999; revisions received Sept 20, 1999; accepted for publication Sept 21, 1999.

Address for reprints: Ren-Ke $\mathrm{Li}, \mathrm{MD}, \mathrm{PhD}$, Toronto General Hospital, University Health Network, CCRW 1-815, 200 Elizabeth St, Toronto, Ontario, Canada, M5G 2C4 (E-mail: RenKe.Li@uhn.on.ca).

Copyright $@ 2000$ by Mosby, Inc.

$0022-5223 / 2000 \$ 12.00+0 \quad \mathbf{1 2 / 6 / 1 0 3 1 4 3}$ ed survival of transplanted cells in both normal myocardium and myocardial scar. ${ }^{4-7}$ Cells that are transplanted close to native cardiomyocytes develop intercalated disks, potentially allowing communication with host cardiomyocytes. ${ }^{1}$ Transplanted cells induce sufficient angiogenesis to allow survival of at least some of the donor cells. Although the mechanism of this angiogenesis remains unclear, the survival of the transplanted cardiomyocytes and the appearance of an abundance of new capillaries attest to the angiogenic potential of cell transplantation. ${ }^{8}$

Xenogeneic, allogeneic, and autologous cardiomyocytes, skeletal muscle cells, and smooth muscle cells have been successfully transplanted into normal or injured myocardium in different species., 4,9-12 We have previously reported that fetal rat cardiomyocytes can improve ventricular function after transplantation into the myocardial scar of adult rats. ${ }^{4}$ Scorsin and colleagues ${ }^{7}$ also found that transplanted cells improved 
heart function after a myocardial infarction. Chiu's group has transplanted skeletal muscle cells into injured canine hearts and demonstrated improved function. ${ }^{12,13}$ Taylor and colleagues ${ }^{14}$ transplanted skeletal muscle cells into rabbit hearts with similar improvement. Cell transplantation may represent a potential therapy for postinfarction ventricular dysfunction.

Although xenotransplanted and allotransplanted cells improved heart function, rejection led to the eventual loss of the transplanted cells despite the use of cyclosporine (INN: ciclosporin), and heart failure recurred. Van Meter and colleagues ${ }^{10}$ have used a porcine model to evaluate the survival of allogeneic and xenogeneic implanted cells. Unfortunately, all of the transplanted cells were destroyed by rejection. Autologous cell transplantation may therefore be the only clinically applicable technique of cell transplantation. To evaluate the potential benefits of autologous cell transplantation, we transplanted cells derived from adult pig hearts back into the same animal after creation of a myocardial infarction by occlusion of the left anterior descending coronary artery (LAD).

\section{Methods}

Experimental animals. Adult female domestic Yorkshire swine $(35 \pm 9 \mathrm{~kg}$ ) (Charles River Canada Inc, Quebec, Canada) were used. All procedures were approved by the Animal Care Committee of the Toronto Hospital and performed according to the "Canadian Council on Animal Care and Use of Laboratory Animals," published by the National Institutes of Health.

Creation of the myocardial infarction. All surgical procedures on swine were done with the use of general anesthesia and continuous electrocardiographic monitoring. Animals were premedicated with ketamine $(20-30 \mathrm{mg} / \mathrm{kg}$, intramuscularly) before induction of anesthesia with $4 \%$ isoflurane. Anesthesia was maintained with $1 \%$ to $2.5 \%$ isoflurane.

In our initial experiments, a myocardial infarction was created by surgical ligation of the LAD $(\mathrm{N}=4)$. However, because of concerns about the potential for postoperative reactive inflammation and creation of epicardial collaterals, this technique was abandoned. The subsequent pigs underwent myocardial infarct generation by interluminal coil occlusion and Gelfoam gelatin sponge embolization of the distal LAD $(\mathrm{N}=16)$ and only results in these animals are presented in this study.

Myocardial biopsy. A flexible bioptome was introduced in retrograde fashion into the left ventricle from the carotid artery under fluoroscopic guidance, and 5 biopsy specimens were obtained from varying sites on the interventricular septum. Tissue samples were placed immediately into ice-cold sterile cell culture dishes containing culture medium for subsequent cell isolation and culture.

Cell isolation, culture, and identification. Under sterile conditions, porcine heart cells were isolated by enzymatic digestion, as we have previously described. ${ }^{15,16}$ The yields from our isolation and culture procedures were evaluated by counting the plated cells $0,7,14$, and 28 days after isolation. Cells were cultured for 4 weeks before transplantation. ${ }^{15,16}$

The heart cells in the culture dish were identified with the use of monoclonal antibodies against troponin I for cardiomyocytes, smooth muscle actin for smooth muscle cells, and factor VIII for vascular endothelial cells, as we have previously described. ${ }^{11,16}$ Briefly, cultured cells were fixed with $100 \%$ methanol at $-20^{\circ} \mathrm{C}$ for 20 minutes. Endogenous peroxidase was then blocked with the use of $3 \%$ hydrogen peroxide for 10 minutes at $42^{\circ} \mathrm{C}$ and $2 \mathrm{~N} \mathrm{HCl}$ for 30 minutes at room temperature. After being rinsed with phosphatebuffered saline solution (PBS) 3 times, the cells were incubated with antibodies against troponin I, smooth muscle actin, and factor VIII in a moist chamber for 16 hours at room temperature. Negative control samples were incubated in PBS without the primary antibodies under the same conditions. After being rinsed with PBS 3 times (15 minutes each), the cells were then incubated with secondary antibody conjugated to peroxidase at $37^{\circ} \mathrm{C}$ for 45 minutes. The samples were washed 3 times (15 minutes each) with PBS and then immersed in diaminobenzidine- $\mathrm{H}_{2} \mathrm{O}_{2}(2 \mathrm{mg} / \mathrm{mL}$ diaminobenzidine, $0.03 \% \mathrm{H}_{2} \mathrm{O}_{2}$ in $0.02 \mathrm{~mL} / \mathrm{L}$ phosphate buffer) solution for 15 minutes. After being washed with PBS, the samples were covered with a crystal mount and photographed.

Cell labeling and preparation for transplantation. To identify the transplanted cells in the recipient myocardium, $10 \%$ of the cultured myocardial cells ( 3 dishes out of a total of 30 dishes for each animal, $\mathrm{N}=3$ ) were labeled with bromodeoxyuridine (BrdU) $(0.1 \mathrm{mg} \mathrm{BrdU} / \mathrm{mL}$ culture medium) for 2 days before transplantation. For transplantation, the cells were dissociated from the culture dish with $0.05 \%$ trypsin in PBS and centrifuged at $570 g$ to remove the trypsin. The cells were resuspended in culture medium at a concentration of $10^{7}$ cells $/ \mathrm{mL}$.

Cell transplantation. Four weeks after infarct creation, the animals were anesthetized and the heart was exposed through a left thoracotomy as previously described. The cell suspension $\left(2 \mathrm{~mL}, 2 \times 10^{7}\right.$ cells $)$ was injected into the infarct region with a tuberculin syringe in a star pattern. One half of the suspension was delivered into the center of the infarct, and the remaining half was divided among 4 or 5 injections in the periphery of the infarct zone in order to facilitate any potential connection between the transplanted cells and the normal myocardium. In the control pigs, only culture medium, without cells, was injected into the infarct region.

Technetium 99m-sestamibi single photon emission tomography $\left({ }^{99 m}\right.$ Tc-MIBI SPECT). Four weeks after infarct creation, and again 4 weeks after transplantation with either cells or culture medium, myocardial perfusion was assessed by injection of $10 \mathrm{mCi}{ }^{99 \mathrm{~m}} \mathrm{Tc}-\mathrm{MIBI}$ SPECT solution (Dupont) 30 minutes before electrocardiogram-gated SPECT scan acquisition, as per our standard clinical protocol. Attenuation was calculated by determining the distance from the detector to the center of the myocardium and counting the 
activity in venous blood samples. Two cardiologists independently reviewed each ${ }^{99 \mathrm{~m}} \mathrm{Tc}-\mathrm{MIBI}$ SPECT scan in a blinded fashion, performing a semiquantitative assessment of perfusion and wall motion in each of 20 segments in cross-sectional views at the apical and midventricular levels and in a vertical long-axis view, as per our usual clinical protocol. Segmental perfusion was graded as $0,1,2,3$, or 4 , indicating no perfusion to normal perfusion. Segmental wall motion was graded as $-1,0,1,2,3$, or 4 , indicating dyskinesis, akinesis, or varying levels of hypokinesis, up to normal wall motion. Both perfusion and wall motion were within normal limits in all animals in the basal regions. All infarct-related scores were obtained in 8 apical, periapical, and midventricular segments. These 8 regions contained all of the infarct areas as assessed by pretransplant ${ }^{99 \mathrm{~m}}$ Tc-MIBI SPECT scans, were the areas into which the cells were injected, and were therefore used to assess any changes occurring with cell transplantation. In addition, the left ventricular end-diastolic and end-systolic volumes were measured with use of a count-based technique and left ventricular ejection fraction calculated.

Evaluation of ventricular function by pressure-volume loops. Four weeks after transplantation, ventricular function in the control animals and animals receiving transplantation was evaluated. Through a sternotomy, a conductance catheter and a micromanometer (Millar Instruments, Inc, Austin, Tex) were inserted into the left ventricular apex. Pressure and volume data were acquired in triplicate as well as data on realtime pressure-volume loops constructed at baseline and during caval occlusion. Hypertonic saline solution was injected and measurements repeated to allow calculation of the required compensation for parallel conductance. From the data, the slopes of the end-systolic pressure-volume relation and the stroke work/end-diastolic volume relation were calculated in order to evaluate systolic function and myocardial performance. Tau, or the time constant of isovolumic pressure decay, was also calculated to evaluate diastolic function.

Morphologic and histologic studies. After the invasive studies of ventricular function were complete, the heart was arrested with potassium chloride and rapidly excised. The atria were removed and the heart was weighed. An intraventricular balloon was introduced into the left ventricle and inflated to $30 \mathrm{~mm} \mathrm{Hg}$ pressure to allow fixation in distention. The coronary arteries were then perfused with $100 \mathrm{~mL} 10 \%$ formaldehyde, and the heart was immersed in formaldehyde solution for 7 days before sectioning for histologic study.

After fixation, the hearts were sliced into 5-mm-thick slices and photographed. Cross-sectional areas of the left ventricular muscle and scar were measured with computed planimetry, and the endocardial-to-epicardial thickness was measured for evaluation of ventricular remodeling. ${ }^{4}$ A cube of tissue from the transplant site measuring $5 \mathrm{~mm}$ on each side was embedded in paraffin and cut into $10-\mu \mathrm{m}$ sections for staining with hematoxylin and eosin, as well as with antibodies against BrdU, to localize the transplanted cells.

For immunohistochemical studies, tissue slices were serially rehydrated in $100 \%, 95 \%$, and $70 \%$ ethanol after deparaffinization with toluene. Endogenous peroxidase in the sample was blocked and the samples were stained with antibodies against BrdU for identification and against troponin I for contractile protein as described earlier.

Statistical analysis. All data are expressed as the mean \pm SD. ${ }^{99 \mathrm{~m} T c-M I B I}$ SPECT-derived perfusion and wall motion scores were analyzed as ordinal data by $\chi^{2}$ analysis. ${ }^{99 \mathrm{~m}} \mathrm{Tc}-$ MIBI SPECT-derived values for left ventricular volume and ejection fraction were subjected to 2-way analysis of variance, evaluating group, time, and group $\times$ time interactive effects. Left ventricular pressure and volume data were subjected to analysis of covariance, evaluating the effect of group on outcomes over a range of ventricular volumes. Body weight and other variables were assessed by $t$ test or, when appropriate, by 2-way analysis of variance.

\section{Results}

Cell isolation and culture. Total weight of the myocardial biopsy specimens was $22.3 \pm 1.0 \mathrm{mg}$ per animal. A mean of $1.8 \pm 0.5 \times 10^{6}$ cells were isolated, and the mean number of cells in culture was $10.7 \pm 2.5$ $\times 10^{6}, 53.6 \pm 9.2 \times 10^{6}$, and $220 \pm 24.8 \times 10^{6}$ on days 7,14 , and 28 of culture, respectively (approximately 6 to 7 doublings). Cells were cultured for 4 weeks before transplantation to increase their number. The mixed cell types were identified by immunocytochemistry. Positive staining for troponin I was noted in $72 \% \pm$ $14 \%$ of the cultured cells, and these cells were assumed to be cardiomyocytes. Staining for smooth muscle actin was observed in $5 \% \pm 5 \%$ of the cells, and these cells were assumed to be smooth muscle cells. Staining for factor VIII was noted in $5 \% \pm 5 \%$ of the cells, and these cells were assumed to be endothelial cells. The remainder of the cells $(18 \% \pm 16 \%)$ were spindle shaped and were presumed to be fibroblasts.

Activity and body weight. Four weeks after scar generation, the swine were randomly separated into 2 groups either to receive cell transplantation $(\mathrm{N}=8)$ or to serve as controls $(\mathrm{N}=8)$. During the 4 weeks after the transplantation procedure, the animal-care technicians noted a marked difference in the activity of the animals, which appeared to correlate with the treatment arm. The pigs receiving transplantation appeared to be more active than control pigs, but these differences were subjective and not easily quantifiable.

Body weight increased slightly in both groups between the time of infarct generation and transplantation (control weight gain, $5.3 \pm 0.9 \mathrm{~kg}$; transplant weight gain, $6.4 \pm 1.3 \mathrm{~kg} ; P=.2$ ). The pigs receiving transplantation, however, gained more weight after cell transplantation than control animals (control weight gain, 7.1 $\pm 1.7 \mathrm{~kg}$; transplant weight gain, $12.6 \pm 1.7 \mathrm{~kg} ; P=0.02$ ).

Regional myocardial perfusion and wall motion by ${ }^{99 m}$ Tc-MIBI SPECT. Pretransplantation and posttransplantation ${ }^{99 \mathrm{~m}} \mathrm{Tc}-\mathrm{MIBI}$ SPECT scans were done on each animal and results compared between times 


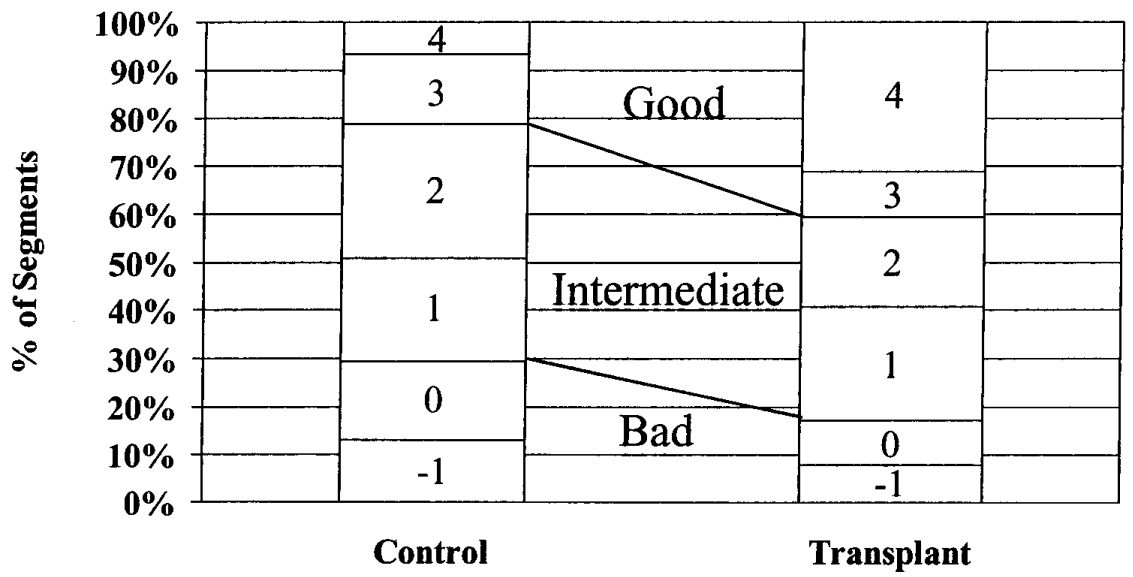

Fig 1. Regional wall motion scores, evaluated by 2 cardiologists blinded to the treatment arm, in the infarct zone 4 weeks after either cell transplantation or injection of culture medium alone. Segmental wall motion was graded as $-1,0,1,2,3$, or 4 , indicating dyskinesis and akinesis $(-1$ and $0, B a d)$, varying levels of hypokinesis $(1,2$, and 3 , Intermediate), and normal wall motion (3 and 4, Good). Wall motion scores were significantly greater in the pigs receiving transplantation than in the control animals.

and between the control and transplant groups. No significant difference in perfusion within the area of infarction was noted between groups before transplantation $(P=.8)$. However, pigs receiving transplantation were more likely to have an improvement in perfusion scores than control pigs $(P=.03)$.

Wall motion scores were not different between groups before transplantation $(P=.13)$. Four weeks after transplantation, wall motion scores were significantly greater in the pigs receiving cell transplantation than in the control pigs (Fig 1). In control pigs, mean wall motion scores tended to fall as the infarct zone became increasingly dyskinetic, whereas pigs receiving transplantation were more likely to have an improvement in wall motion scores $(P=.048)$.

Count-based scintigraphic analysis of left ventricular ejection fractions demonstrated no difference between groups either before transplantation $(P=.66)$ or 4 weeks after transplantation $(P=.4)$.

End-systolic elastance, preload-recruitable stroke work, and tau. From the pressure-volume loops constructed 4 weeks after transplantation, either the preload-recruitable stroke work, or the slope of the left ventricular stroke work/end-diastolic volume index relation $\left(\mathrm{M}_{\mathrm{sw}}\right)$, and end-systolic elastance, or the slope of the end-systolic pressure-volume relation, were calculated. Preload-recruitable stroke work was significantly greater in the pigs receiving cell transplantation than in the control pigs (transplant, $48 \pm 3 \mathrm{~mm} \mathrm{Hg}$; control, $39 \pm 2 \mathrm{~mm} \mathrm{Hg} ; P=.009)$. End-systolic elastance was also significantly greater in the pigs receiving cell transplantation (transplant, $5.3 \pm 0.6 \mathrm{~mm} \mathrm{Hg} \cdot \mathrm{mL} \cdot \mathrm{m}^{2}$; control, $\left.3.2 \pm 0.7 \mathrm{~mm} \mathrm{Hg} \cdot \mathrm{mL} \cdot \mathrm{m}^{2} ; P=.02\right)$. Tau, or the time constant of isovolumic pressure decay, was not different between groups (transplant, $28 \pm 3$; control, $26 \pm 5 ; P=.4$ ).

Histologic and morphometric studies. Computed planimetric analysis indicated that the scar area in the control group $(19.6 \% \pm 6.0 \%$ of total left ventricular free wall) was slightly greater $(P=.02)$ than that of pigs in the transplant group $(13.6 \% \pm 3.5 \%$ of total left ventricular free wall). In the center of the infarct zone, the thickness of the scar area was significantly greater in the pigs receiving transplantation than in the control animals (transplant, $6.6 \pm 2.8 \mathrm{~mm}$; control, $3.5 \pm 1.1$ $\mathrm{mm} ; P=.02)$. After the hearts were excised, the ventricular volumes at $30 \mathrm{~mm} \mathrm{Hg}$ distention were significantly lower in the transplant group $(42 \pm 9 \mathrm{~mL})$ than in the control group $(56 \pm 8 \mathrm{~mL})(P=.045)$.

Histologic evaluation of myocardial sections stained with hematoxylin and eosin demonstrated greater cellularity in the scar tissue of hearts from the transplant group than in that of hearts from the control group (Fig 2 ). Ten percent of the cultured cells had been prelabeled with BrdU before transplantation, and BrdUlabeled cells were identified within the infarct zone 4 weeks after cell transplantation (Fig 3). In this model of transplantation of autologous cells, we did not observe any histologic evidence of rejection at 4 weeks.

\section{Discussion}

We have previously reported that allogeneic fetal rat cardiomyocytes, when transplanted by needle injection into the center of a cryoinjury-induced myocardial scar, 

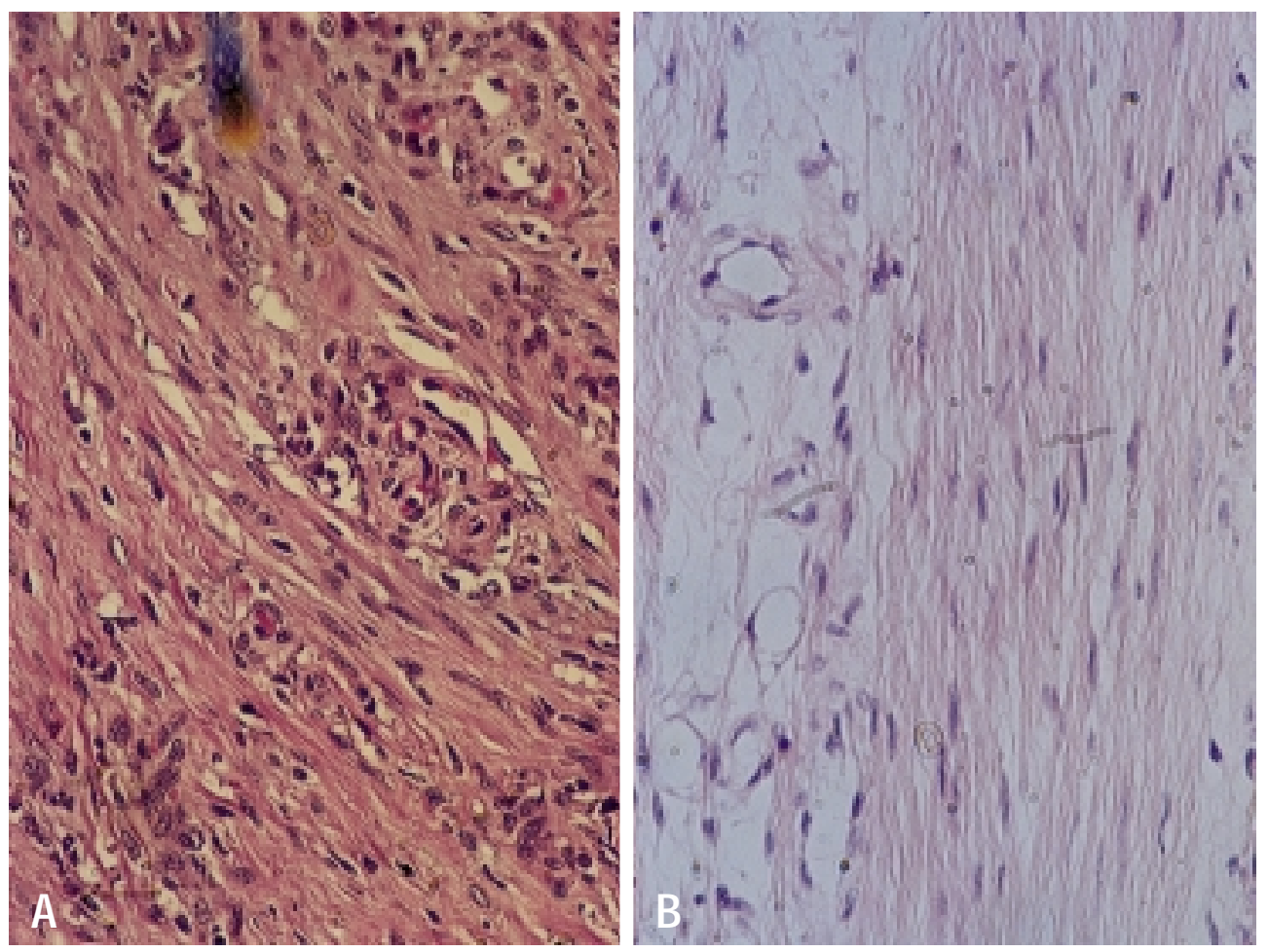

Fig 2. Photomicrographs of representative sections from the infarct zones of (A) cell transplantation and (B) culture medium transplanted porcine hearts in which a LAD myocardial infarction was created. Control hearts demonstrated predominantly fibrous scar in the infarct zone, whereas transplanted hearts had greater cellularity (hematoxylin and eosin stain, original magnification $\times 400$ ).

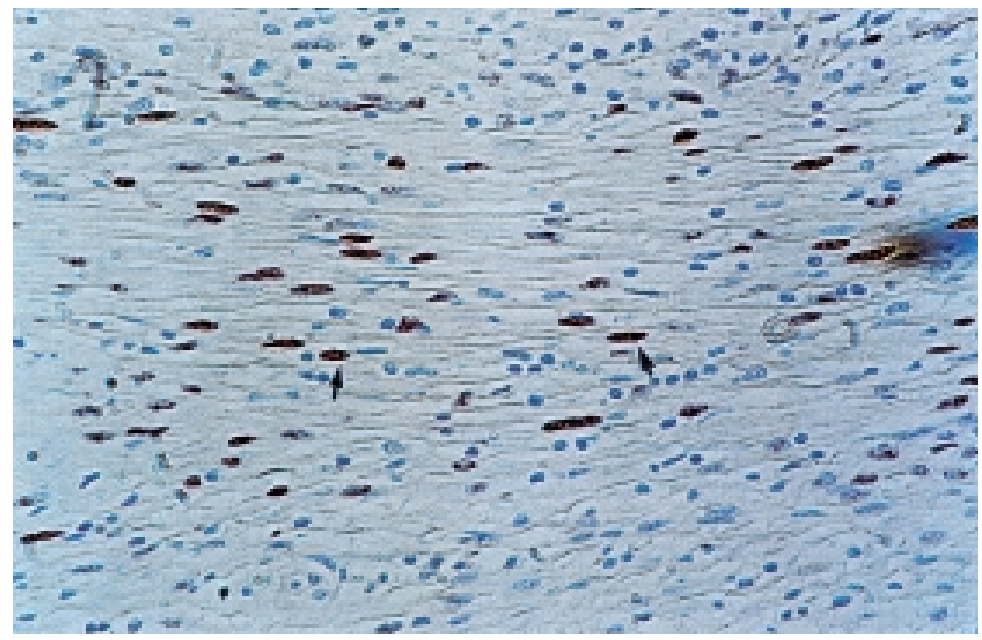

Fig 3. Photomicrograph of a section from a porcine heart in which $10 \%$ of the cultured heart cells had been prelabeled with BrdU in vitro before transplantation. Staining for BrdU was observed in cells throughout the infarct zone (arrows), demonstrating some of the cells transplanted 4 weeks previously (original magnification $\times 400$ ).

can significantly improve ventricular function. ${ }^{4}$ In addition, we reported that allogeneic gastric-derived smooth muscle cells also survive after transplantation into this cryoinjured myocardial scar tissue, where they limited ventricular dilatation after injury, possibly by restoring myocardial elasticity. ${ }^{11}$ Smooth muscle cell transplantation also improved left ventricular function in a Langendorff preparation. However, our present study is 
the first, to our knowledge, to demonstrate that the transplantation of autologous heart cells into a myocardial infarction results in survival of the transplanted cells.

The advantage of transplanting autologous cells is the elimination of the immunosuppressive regimen required for maintenance of allotransplants in vivo. Histologic examination revealed no evidence of rejection at the sites of transplantation in these pigs in which autologous cells had been harvested from the ventricular septum for expansion in culture before reimplantation. We were therefore able to avoid the confounding effects of rejection and eventual destruction of the transplanted cells in our evaluation of the effect of cell transplantation on ventricular function. We believe that autotransplantation may be the most clinically feasible strategy by which cell transplantation may eventually be applied to human beings.

In this experiment, we obtained a mixture of cell types from our septal biopsy specimens and expanded these cells in culture for 4 weeks. Before cell transplantation, we identified these multiple cell types by immunohistochemical staining for proteins specific to cardiomyocytes, smooth muscle cells, and endothelial cells in order to quantitate their relative proportions. A combination of cells consisting of cardiomyocytes, smooth muscle cells, vascular endothelial cells, and myocardial fibroblasts was transplanted into the infarct zone in this series of experiments. BrdU-prelabeled cells could be identified in the infarct zone 4 weeks after transplantation. However, because it was not possible to simultaneously stain for BrdU and for the cell type-specific proteins in histologic sections of the hearts that received cell transplantation, it was not possible to definitively determine the cell type of the transplanted cells persisting in the infarct zone after transplantation.

The thickness of the ventricular wall in the middle of the scar tissue in hearts receiving transplantation was significantly greater than that in the control hearts, and under histologic examination this difference appeared to be a result of increased cellularity of the infarct zone rather than greater thickness of fibrous scar. This alteration of the process of ventricular remodeling after myocardial infarction may have been caused by increased elasticity of the scar region and possibly by increased formation of extracellular matrix. The thicker scar prevented scar expansion and limited ventricular dilatation. This conclusion was supported by our finding that the myocardial scar area in the control group was greater than that in the transplant group and that the hearts receiving cell transplantation had smaller passive left ventricular chamber volumes compared with the control hearts.
We did not quantitate the angiogenesis within the infarct zone induced by heart cell transplantation. Blood vessels were seen in the region that contained the transplanted cells. Angiogenesis may be crucial to the survival of the transplanted cells and may have contributed to the improvement in ventricular function noted after cell transplantation. Future studies will quantify the capillary density and blood flow.

In this study, the load-insensitive indices of global systolic left ventricular function were significantly greater in the cell transplantation group than in the control animals 4 weeks after transplantation. This correlated with the noninvasive evaluation of regional ventricular function in the infarct zone, because the wall motion scores (graded by 2 cardiologists blinded to the treatment arm) were also significantly greater after cell transplantation. We found no difference in tau, the time constant of pressure decay during isovolumic relaxation, between groups. These findings contrast with those of previous small animal studies in rats and rabbits in which cell transplantation has resulted primarily in changes in diastolic function and ventricular remodeling. ${ }^{4,14}$ In these small animals, improvement in indices of systolic function attributable to cell transplantation has been difficult to demonstrate.

One of the limitations of the present study is the size of the myocardial infarction generated by our coil occlusion technique. Although the anatomy of the porcine heart is in many ways similar to that of the human heart, the porcine heart is very sensitive to myocardial infarction. We noted a mortality rate of $15 \%$ with infarct creation in our current protocol. A larger infarction would improve our ability to evaluate the effects of cell transplantation, but the mortality rate would also be significantly greater. We plan to use our current porcine model to perform further, long-term studies of the safety and efficacy of cell transplantation to improve ventricular function in infarcted hearts.

\section{REFERENCES}

1. Soonpaa MH, Koh GY, Klug MG, Field LJ. Formation of nascent intercalated disks between grafted fetal cardiomyocytes and host myocardium. Science 1994;264:98-101.

2. Li R-K, Yau TM, Sakai T, Mickle DAG, Weisel RD. Cell therapy to repair broken hearts. Can J Cardiol 1998;14:735-44.

3. Leor J, Prentice H, Sartorelli V, et al. Gene transfer and cell transplant: an experimental approach to repair a "broken heart." Cardiovasc Res 1997;35:431-41.

4. Li R-K, Jia Z-Q, Weisel RD, et al. Cardiomyocyte transplantation improves heart function. Ann Thorac Surg 1996;62:654-61.

5. Koh GY, Soonpaa MH, Klug MG, Field LJ. Long-term survival of AT-1 cardiomyocyte grafts in syngeneic myocardium. Am J Physiol 1993;264:H1727-33.

6. Leor J, Patterson M, Quinones MJ, Kedes LH, Kloner RK. 
Transplantation of fetal myocardial tissue into the infarcted myocardium of rat: a potential method for repair of infarcted myocardium? Circulation 1996;94(Suppl):II332-6.

7. Scorsin M, Marotte F, Sabri A, et al. Can grafted cardiomyocytes colonize peri-infarct myocardial areas? Circulation 1996;94 (Suppl):II337-40

8. Kim EJ, Li R-K, Weisel RD, et al. Angiogenesis induced by endothelial cell transplantation [abstract]. Circulation 1998;98 (Suppl):I407.

9. Watanabe E, Smith DM, Delcarpio JB, et al. Cardiomyocyte transplantation in a porcine myocardial infarction model. Cell Transplant 1998;7:239-46.

10. Van Meter CH, Claycomb WC, Delcarpio JB, et al. Myoblast transplantation in the porcine model: a potential technique for myocardial repair. J Thorac Cardiovasc Surg 1995;110:1442-8.

11. Li R-K, Jia Z-Q, Weisel RD, Merante F, Mickel DAG. Smooth muscle cell transplantation into myocardial scar tissue improves heart function. J Mol Cell Cardiol 1999;31:513-22.

12. Chiu RC, Zibaitis A, Kao RL. Cellular cardiomyoplasty: myocardial regeneration with satellite cell implantation. Ann Thorac Surg 1995;60:12-8.

13. Marelli D, Deschene C, Al-Elfy M, Kao R, Chiu R. Cell transplantation for myocardial repair: an experimental approach. Cell Transplant 1992;1:383-90.

14. Taylor DA, Atkins BZ, Hungspreugs P, et al. Regenerating functional myocardium: improved performance after skeletal myoblast transplantation. Nat Med 1998;4:929-33.

15. Li R-K, Mickle DAG, Weisel RD, Zhang J, Mohabeer MK. In vivo survival and function of transplanted rat cardiomyocytes. Circ Res 1996;78:283-8.

16. Li R-K, Mickle DAG, Weisel RD, et al. Human pediatric and adult ventricular cardiomyocytes in culture: assessment of phenotypic changes with passaging. Cardiovasc Res 1996;32:362-73.

\section{Discussion}

Dr Ray Chu-Jeng Chiu (Montreal, Quebec, Canada). In the abstract published for this meeting, as well as in the presentation, the authors stated that the ejection fraction was statistically significantly improved in the pigs receiving cell implantation, in contrast to the data presented in the manuscript, which indicated that the ejection fraction was not statistically better. If the manuscript is correct and the ejection fraction did not differ significantly, this leads to the following question. According to your paper, the hearts receiving cell implantation were smaller; that is, they had statistically significantly smaller diastolic volumes than the control hearts. If the ejection fractions were about the same, were the stroke volumes and the cardiac output also similar in the 2 groups, as could be expected? If they were not different, then why would the cell transplantation make the pigs so much happier and gain more weight?

The other question is a crucial one in the minds of many of us who are following your work with great interest. You stated that you took very small biopsy samples of the myocardium and multiplied the cell number tremendously during culture before implantation. Although there was some contamination by other types of cells, most of them, you thought, were cardiomyocytes, and as I heard earlier in another paper from this group, they were identified histochemically by troponin I and myosin isoforms. However, it is generally believed that normal mature cardiomyocytes are terminally differentiated cells, and they do not divide in vivo. Therefore their phenotype must have been changed if in fact somehow you were able to make them proliferate in the culture. When normally nondividing cells are converted into a cell line and immortalized in vitro, there is always the concern of oncogenicity in vivo. Therefore my question is, what evidence do you have that the modified cardiomyocytes are safe for implantation in patients without the risk of malignancy?

Dr Li. In these experiments, the cells isolated from our myocardial biopsy samples proliferated in vitro. Although the cells did not have sarcomeres, immunohistochemical staining with antibodies against troponin I and myosin heavy chains showed that most of the cultured cells contained these contractile proteins. Our previous study (Cardiovasc Res 1996;32:362-73) demonstrated that the intracellular content of these contractile proteins progressively decreased while the cells were maintained in culture for 3 months. Therefore, the cells, we believe, are dedifferentiated cardiac muscle cells.

In the study we reported today, the cells were stained with antibodies against contractile proteins before transplantation. Most of the cells contained these contractile proteins and were subsequently transplanted into the infarct zone, where they survived for the 4-week duration of our study.

We were also concerned about continuing cellular proliferation after transplantation. Therefore we evaluated transplanted cell proliferation in vivo in a long-term study (3 months) (Circ Res 1996;78:283-8). Cultured heart cells were implanted into the subcutaneous tissue of an adult rat. Cell proliferation was evaluated with the use of BrdU labeling, and echocardiography was used to measure the growth of the transplanted tissue. We found that the cells proliferated only in vitro, and not in vivo. After transplantation the cells underwent hypertrophy but no further division. No BrdU uptake was detected in the implanted cells.

In response to your question about heart function, we encountered some difficulty with our porcine infarct model. In the first group of animals we studied by ${ }^{99 \mathrm{~m}} \mathrm{Tc}-\mathrm{MIBI}$ SPECT scanning, we found that the control animals had a decrease in ejection fraction and cardiac output after media transplantation and the infarct area thinned and dilated after 4 weeks. In the animals that received transplantation with heart cells, the infarct region did not thin or dilate and the ejection fraction and cardiac output were well preserved. This information formed the basis of our abstract. We then did additional animal studies. In the control group we found a consistent thinning and dilatation of the infarction region by morphometric examination. However, the hemodynamic response, as measured by ${ }^{99} \mathrm{~m}$ Tc-MIBI SPECT scans, did not show a consistent decrease in either ejection fraction or cardiac output.

In our final analysis, we did not find a difference in the ejection fraction between the transplant and control groups, but we did find a difference in load-independent indices of function, scar thickness, chamber volume, and weight gain. We believe that heart cell transplantation altered the remodeling process after a myocardial infarction and permitted better cardiac function than that of the control animals. 